\title{
A 21 Year Old Female with atypical presentation of TB Peritonatis
}

\author{
By Manji Mohamed MD3 2006/07 \\ Hasuji Zainab MD3 2006/07
}

\section{INTRODUCTION}

The incidence of tuberculosis is sharply rising, and tuberculous peritonitis is often diagnosed late in the course of the disease, resulting in undue patient morbidity and mortality. Peritoneal tuberculosis is a common disease in underdeveloped countries and is the cause of $20-50 \%$ of all cases of ascites'. In industrialized countries, a revival of tuberculosis has been observed in recent years in parallel with the HIV epidemic ${ }^{2}$. The disease is generally observed in young adults in the third or fourth decade ${ }^{3}$. The clinical presentation is generally with ascites and fever associated with abdominal pain and poor general health ${ }^{4-6}$.

In majority of cases, it is a secondary involvement and there is some primary focus elsewhere in the body. Though sometimes the primary focus remains obscure, almost always it is later demonstrated to be in the lung. Majority of cases are due to reactivation of latent peritoneal tuberculosis which had developed by haematogenous spread from a pulmonary focus. ${ }^{7}$

On the whole, tuberculous peritonitis is no more a dangerous condition due to the advent of proper anti tubercular drugs. Usually after 1 year of treatment the patients become asymptomatic ${ }^{7}$. But TB peritonitis often heals with formation of dense fibrous adhesions which are often liable to future development of intestinal obstruction, ureteral stenosis, ectopic pregnancy and sterility in women ${ }^{8}$.

\section{CASE REPORT}

21 year old lady presented with abdominal distension and pain for two weeks. Symptoms began 3 days post delivery. Symptoms were associated with (infrequent) bilious vomiting (without nausea), significant weight loss and fever. Abdominal pain was not found to radiate to any part of the body and stool was of normal colour. She did not report any hereditary diseases. On examination; she was weak with conjuctival pallor, she had rash like lesions on her right leg and mild pitting pedal edema on the left leg.She was not dyspnoeic, not jaundiced, nor was there oral thrush or finger clubbing and did not have any lymph node enlargement (including Virchow's nodes).

The abdominal distension was tender on palpation and an umbilical ulceration with irregular margins and purulent discharge was noted. Shifting dullness and fluid thrill tests were positive, there was no evidence of hepatosplenomegally. Bowel sounds were exaggerated

Apart from a dull percussion note over her left lower lung zone, the rest of the respiratory exam was also normal with a RR of 18/min. Homann's test for Deep vein thrombosis was negative.FBP of the patient showed that the patient was anaemic with mild Leukocytosis. Her ESR was $110 \mathrm{~mm} / \mathrm{hr}$. Liver function tests were normal except for elevated GGT and LDH.

Chest X-Ray revealed pleural effusion in the left lower zone and abdominal $x$-ray revealed a gasless abdomen. Abdominal / pelvic ultrasound showed a complex ovarian cyst measuring $18 \mathrm{~cm}$ by $13 \mathrm{~cm}$, fluid in the pouch of Douglas, thickened bowel loops with dilated bowels (significant for Intestinal obstruction) and mild fatty change in the liver. The acitic tap, sputum, and swab from the umbilical discharge were all negative for Mycobacterium tuberculosis. The ascitic tap was straw coloured transudate and revealed PMN's and leucocytes. TB antibodies were also negative for the patient. Tumor markers namely AFP and CA 125 were all within normal range. ELISA for HIV was also negative.

\section{DISCUSSION}

This case was initially thought to be a case of intestinal obstruction suggested by the bilious vomiting and the dilated intestinal loops as seen on ultrasound. Since the patient did not present with constipation, a feature very typical for obstruction, the diagnosis looked dubious.

Ultrasounds of the patient also revealed a complex ovarian mass measuring $18 \mathrm{~cm}$ by $13 \mathrm{~cm}$. Ascites was also present and contributed to the distended abdomen. Cystadenocarcinoma of the Ovary was considered a possibility based on the ultrasound findings. This is a malignant ovarian tumor of epithelial origin. It is rare in women under the age of 30 years thus making it a less likely diagnosis in this patient. This patient had normal levels (less then $35 \mathrm{U} / \mathrm{ml}$ ) for CA 125. Levels more then $100 \mathrm{U} / \mathrm{ml}$ are significant for malignant disease. 
Based on ultra sound findings, two other possibilities were considered; Endometriosis and Dermoid cyst of the ovary. The Dermoid cyst is a benign germ cell tumor and is most common in young women. The typical mammilary processes suggestive of this condition on ultrasound were not seen in this patient. Endometriosis is an inflammatory condition characterised by the presence of endometrial tissue in ectopic sites. In this case, the patient did not complain of dysmenorrhoea nor could diffuse low level echoes be seen on ultrasound, suggesting against this diagnosis.

The rapid progression of the disease was suggestive of some underlying abdominal malignancy. However the absolutely abrupt onset of the disease ( 3 days after delivery) hinted on an inflammatory process. Apart from this, Troissier's sign (enlarged left supraclavicular nodes - Virchow's nodes), was negative in this patient. When present it is usually an indication towards an abdominal malignancy. AFP levels were also within normal range, suggesting against hepatic metastases to the ovary.

The patient had ovarian involvement associated with ascites and pleural effusion. Meig's syndrome was therefore also considered. The ovarian involvement in this syndrome is a fibroma. This condition is benign and resolves spontaneously upon surgical resection of the tumor. With this patient, symptoms began to disappear (upon starting anti TB medication) despite no surgical attempt being made to remove the tumor suggesting that this was not Meig's syndrome.

The final diagnosis reached was that of TB peritonitis. In our settings, Tuberculosis is confirmed only when AFB can be demonstrated from body secretions (e.g. sputum, ascitic fluid, pus fluid) or if growth of mycobacteria can be observed upon culture. In our case, neither sputum nor the ascitic fluid was found to have AFB and no growth was observed on culture. TB antibodies were also negative. She was started on anti TB medication intensive phase for 2 months with RHZE (Rifampicin, Isoniazid, Pyrazinamide and Ethambutol) followed by a continuation phase of 4 months which included Rifampicin and Isoniazid on an index of suspicion based on the high prevalence of TB in our setting. In two weeks time, her ascites, pleural effusion and pedal edema had resolved suggesting in retrospect that this was a case of TB peritonitis.

There is no specific biological marker for peritoneal tuberculosis. An inflammatory syndrome, with hyperleukocytosis, accelerated ESR, and elevated Creactive protein with hypochromic microcytic anemia is common. The tuberculin skin test, which was not performed in our patient, is positive in 40 to $85 \%$ of patients, depending on reports', and does not contribute to diagnosis. Study of the ascitic fluid can be helpful; this is usually an exudative effusion with predominantly lymphocytes $\mathrm{e}^{9,10}$ The tuberculosis bacillus is identified on direct examination of the ascitic fluid in only $5 \%$ of patients ${ }^{1,11}$ and culture crucial for diagnosis.At the present time, several studies have emphasized the importance of assaying adenosine deaminase (ADA) activity in ascitic fluid using a simple noninvasive technique. The diagnostic values are excellent (98\% specificity, 96\% sensitivity, $95 \%$ positive predictive value and $98 \%$ negative predictive value) ${ }^{11}$, 12,13. LDH assay in ascitic fluid is a sensitive test ( $90 \%$ for $>90 \mathrm{IU} / \mathrm{L})$ but poorly specific $(14 \%)^{14}$. Association of ascites, adherences, peritoneal deposits and thickening is highly suggestive of tuberculosis ${ }^{17}$. Late complications, particularly if diagnosis and treatment are delayed, include peritoneal fibrosis and adherences which can lead to ureteral stenosis, intestinal obstruction, ectopic pregnancy and sterility in women ${ }^{8,18}$.

\section{CONCLUSION AND RECOMMENDATION:}

TB peritonitis may be fatal but is medically cured if diagnosed in a timely fashion. It is essential that the clinician suspect the disease in appropriate patients. A chest $x$-ray should be performed in all patients to search for active pleuropulmonary lesions or sequelae which could provide diagnostic clues since active pulmonary tuberculosis is associated with peritoneal tuberculosis in 4 to $50 \%$ of patients ${ }^{1}$. The use of ADA as an indicator should also be considered in the light of its diagnostic acumen in diagnosing the condition early versus its cost effectiveness. 


\section{REFERENCES:}

1. Marshall JB. Tuberculosis of the gastrointestinal tract and peritoneum. Am J Gastroenterol 1993; 88: 989-99.

2. Guidugli RB, Siqueira SA, Senise JF, Silva AJ, Hamrick P, Figueiroa NR. Abdominal mycobacterial infection in acquired immunodeficiency syndrome patients. Sao Paulo Med J 1995; 113: 895-902.

3. Peghini M, Rajaonarison P, Pecarrere JL, Razafindramboa H. Peritoneal tuberculosis in 55 cases. Arch Inst Pasteur Madagascar 1995; 62: 99-102.

4. Manohar A, Simjee AE, Haffejee AA, Pettengell KE. Symptoms and investigative findings in 145 patients with tuberculous peritonitis diagnosed by peritoneoscopy and biopsy over a five year period. Gut 1990; 31: 1130-2.

5. Bhargava DK, Shriniwas, Chopra P, Nijhawan S, Dasarathy S, Kushwaha AK. Peritoneal tuberculosis: laparoscopic patterns and its diagnostic accuracy. Am J Gastroenterol 1992; 87: 109-12.

6. Sandikci MU, Colakoglu S, Ergun Y, Unal S, Akkiz H, Sandikci $S$, et al. Presentation and role of peritoneoscopy in the diagnosis of tuberculous peritonitis. J Gastroenterol Hepatol 1992; 7: 298-301.

7. A concise textbook of surgery, by S. Das, $4^{\text {th }}$ ed, pp 10171018

8. Robaday S, Belizna C, Kerleau JM, Heron F, Cailleux N, Lecomte $F$, et al. Peritoneal tuberculosis: une entité toujours présente. A propos de 4 observations. Rev Med Interne 2005; 26: 738-43.

9. Verspyck E, Struder C, Wendum D, Bourgeois D, Lariven S, Marpeau L. Peritoneal Tuberculosis. Ann Chir 1997; 51: 375-8.
10. Balian A, de P, I, Belloula D, Barthelemy P, Montembault S, Girard T, et al. Abdominal Tuberculosis. Press Med 2000; 29: 994-6.

11. Dhiman RK. Tuberculous peritonitis: towards a positive diagnosis. Dig Liver Dis 2004; 36: 175-7.

12. Sathar MA, Simjee AE, Coovadia YM, Soni PN, Moola SA, Insam B, et al. Ascitic fluid gamma interferon concentrations and adenosine deaminase activity in tuberculous peritonitis. Gut 1995; 36: 419-21.

13. Burgess LJ, Swanepoel CG, Taljaard JJ. The use of adenosine deaminase as a diagnostic tool for peritoneal tuberculosis. Tuberculosis (Edinb) 2001; 81: 243-8.

14. Shakil AO, Korula J, Kanel GC, Murray NG, Reynolds TB. Diagnostic features of tuberculous peritonitis in the absence and presence of chronic liver disease: a case control study. Am J Med 1996; 100: 179-85.

15. Protopapas A, Milingos S, Diakomanolis E, Elsheikh A, Protogerou A, Mavrommatis K, et al. Miliary tuberculous peritonitis mimicking advanced ovarian cancer. Gynecol Obstet Invest 2003; 56: 89-92.

16. Wang YC, Lu JJ, Chen CH, Peng YJ, Yu MH. Peritoneal tuberculosis mimicking ovarian cancer can be diagnosed by polymerase chain reaction: a case report. Gynecol Oncol 2005; 97: 961-3.

17. Dafiri R, Imani F. Abdominal Tuberculosis. Encycl Med Chir (Scientific Editions Elsevier SAS, Paris) Radiodiagnostic tests, 33-010-A-30, 2001, 12p.

18. Bouzaidi S, Ben Hammouda I, Ben Salem M, Ben Yedder J, Trabelsi S, Moussa A, et al. Peritoneal Tuberculosis: a report of 85 cases. Mag Med 2002; 22: 274-77. 